\title{
Modelling of Dynamic Interactions in the Fuel Rail for the Aircraft Diesel Engine
}

\author{
Rafał Sochaczewski', Paweł Magryta ${ }^{1 *}$ \\ 1 Department of Thermodynamics, Fluid Mechanics and Aviation Propulsion Systems, Lublin University of \\ Technology, Nadbystrzycka 36, 20-618 Lublin, Poland \\ * Corresponding author's e-mail: p.magryta@pollub.pl
}

\begin{abstract}
The paper reports a computer model for simulating dynamic responses in fuel rail of aircraft diesel engine. The fuel system was designed for use in a two-stroke compression-ignition engine with opposite pistons. The methodology of building a fuel system model in the AVL Hydsim program and the results of simulation studies were presented. Determination of dynamic phenomena in the fuel rail required the construction of a model of the entire supply system. It is a common rail system with a three-section positive displacement pump and electromagnetic fuel injectors. The system is also equipped with a PID regulator to maintain the present pressure in the fuel rail. For the purposes of the research, two structures of the fuel rail were developed. They differ in dimensions, spacing of the outlet ports and location of the high-pressure connection. The research allowed determining the interactions between the geometry of the fuel rail and the supply method with the fuel pressure and injector mass flow rate. This will optimise the design of the fuel rail for the three-cylinder engine power supply system.
\end{abstract}

Keywords: diesel engine, two-stroke, common rail, modeling

\section{INTRODUCTION}

The use of diesel engines in the 20th century caused their dominance in such areas of transport as trains, power generators, agriculture, construction, mining, heavy vehicles, military vehicles and submarines. This was because this kind of an engine has higher chemical energy conversion efficiency from the same volume of fuel than a spark ignition engine. In addition, diesel fuel is safer than gasoline, because it has a higher value of boiling point and is less volatile. However, among the many advantages of diesel engines, their disadvantages cannot be ignored. The main disadvantages that have not allowed for wide application in the aviation sector is their high mass and excessive noise they emit. In addition, the engines have lesser acceleration capability and emit significantly more nitrogen oxides and particulates. Trying to eliminate these disadvantages, many new technologies were developed in the early 1990s, which are still used in the diesel engines today, such as the Common Rail system, VGT variable geometry turbocharger, EGR exhaust gas recirculation system, selective SCR catalytic reduction, or particulate filter DPF as described by $[8,14]$. However, the use of new materials has significantly reduced the weight of the compression-ignition engines. As a result, the use of this type of engines in aviation is becoming real and increasingly popular last years. However, one fact cannot be ignored, is that since the beginning of the 21 st century, the automotive industry has been showing a trend of departing from the construction of compression-ignition engines, mainly due to the increased emissions of harmful exhaust compounds. Perhaps the alternative to using these engines at their current stage of development will be aviation.

For this to happen, however, it must be possible to reduce the mass of this type of engine [12], which seems to be possible with the use of the 
opposite piston engine design. Research is carried out all over the world on this type of constructions, among others by $[15,16,18]$. For example, the ways of cooling these engines by [6] are analyzed, which is a key issue in this type of construction.

Additionally, the scientists at Lublin University of Technology, are working on a diesel engine with the opposite pistons construction, in which the Common Rail system was used to supply diesel fuel. While some elements of the fuel system such as the injector or high pressure pump have been implemented in the automotive industry, due to the proven and unreliable design, less complex elements can be designed in terms of optimizing their mass. Therefore, the research work carried out also focuses on solving the injection control method problems, in particular the effect of capacity, shape and other characteristics parameters of the fuel tank (CR rail), which was presented in this article.

The size, type and shape of the fuel tank are some of the key issues in terms of injection control in a diesel engine. In addition to this element, the fuel supply system includes: fuel tank, low pressure pump, high pressure pump, pressure sensor in the fuel rail, fuel lines and injectors. A lot of other parameters affecting the engine's operation depend on the parameters of the fuel rail. At constant load and engine speed, higher fuel rail pressure causes faster fuel injection (and droplet size reduction) or increases fuel mass flow, which increases the combustion temperature, which in turn raises the NOx and PM emissions. However, higher pressure results in greater combustion efficiency and reduced fuel consumption. Considering the phenomena occurring in the flow of fuel through the fuel rail, this aspect of control is important, also due to the dynamic phenomena occurring in the injector, which was analyzed by [21], as well as in the fuel pump as studied by [22]. Sochaczewski [21] analyzed the mass of fuel per one fuel injection process and determined the effective flow field, which allowed the atomizer to be optimized. In contrast, the publication by [22] focused on developing a model that enables the simulation of pump operation under various conditions defined by the shaft speed, discharge pressure, pump actuator settings as well as fuel properties. In both articles above, the AVL Hydsim simulation tool was used.

The legitimacy of conducting simulation tests for high-pressure diesel fuel injection was also confirmed by $[9,4,7,24]$, where the authors proved the convergence of simulation and real tests.

There are also works in which the dynamic response of the injector was studied in detail, which affects its output. Researchers [19, 9, 5] confirmed the validity of modeling $\mathrm{CR}$ injection systems, where very small error values between real experiment and modeling of flow through the injector under dynamic conditions were demonstrated. However, in the publication [10], authors focused on describing the kinematic energy losses resulting from dynamic phenomena in the injector. Modeling of these phenomena yielded the results which were comparable with real ones [11]. However, they analyzed other issues than their predecessors. In this position, the authors focused on analyzing the impact of the accuracy of the injector parts on its mode of operation and showed a significant impact of the tolerance of execution on the injector output.

Other papers present the flow measurements of the fuel rail itself. In one of these articles, Balluchi et al. [3] explored a new control method in which a fuel pressure sensor was placed in front of a high pressure pump, which allowed regulating the fuel flow depending on the engine operating point. In another article [17], the method of diagnosing a fault in the fuel system based on the data from the fuel rail pressure measurement was analyzed. The authors were able to determine the moment of occurrence of the defect based on the pressure measurement in the fuel rail, but they were not able to determine the place of its occurrence (whether it is damage to the injector, pump or other CR system).

There are also articles where the use of CR systems for the use of alternative fuels was proposed, e.g. such as $[12,20,23]$. This solution uses a CR rail for hydrogen supply. Rail pressure fluctuations and mass flow through injectors were investigated.

\section{MODEL DESCRIPTION}

\section{Model assumptions}

The tests of the fuel supply system were carried out in the AVL BOOST Hydsim software. It is a module dedicated to dynamic analyses of hydraulic and hydro-mechanical systems as well as control systems. It enables modeling of gasoline, heavy oil and alternative fuel supply systems. In addition, it is supplemented with new applications such as hydraulic transmissions, valve control and 
actuators. It can be used to simulate multiphase injection and systems containing control units $[1,2]$.

The model was developed in an environment with component libraries that allows building the structure of any fuel supply system. The model calculates the fuel parameters in individual elements of the fuel apparatus. This enables to visualize the simulation results in the form of flow parameters for hydraulic elements (pressure, temperature, volumetric or mass flow, geometric and effective flow area, flow resistance, vapor bubbles, cavitation coefficient) and mechanical (coordinates, speed, acceleration, forces dynamic and torque, kinematic parameters). The calculation results are available for the crankshaft angle or time of rotation domain.

During the construction of the system model, the following assumptions and simplifications were adopted resulting from the specifics of the program operation:

- one-dimensional model taking into account only the length and diameter of flow elements,

- geometrical orientation of system elements has no effect on their operation,

- the wall temperature of the elements is constant,

- fuel flow includes only elements with a circular cross-section,

- the mechanical boundary condition defines the position or speed in one direction only and is a constant value,

- system elements were adopted as non-deformable elements (coordinates and speed between the input and output states are the same),

- the cooperating elements take into account the losses of fuel leaks using the model based on the Hagen-Poiseuille law, assuming a laminar flow through the annular gap the value of which changes as a function of fuel pressure,

- the high pressure pump is a positive displacement piston pump,

- the pumping sections in the high pressure pump are identical in geometry,

- volume connections were modeled with cylindrical elements taking into account the friction losses determined by the Laplace transformation,

- $33 \%$ of the mass of the spring is added to the mass of the moving element, which is affected by the spring, a mass constituting,

- VCO injector atomizer - Valve Closes Orifice,

- coefficient of flow loss through the injector holes was 0.83 ,
- the injector control valve was modeled as a throttle in which the flow field is a function of time.

\section{Fuel supply system model}

In order to conduct fuel tank tests, a complete fuel supply system was built that reflects the real working conditions. The model consists of a sub-model of a high pressure pump, a fuel tank, three injectors and a control system. The whole system is shown in Figure 1. A pump submodel with three sections was used due to the presence of three fuel injector sub-models. This enables synchronization of the pressing with the injection process and thus the elimination of the impact of the pressing process on the output of the injectors.

The exact description of the pump and injector submodel was presented in two articles by [21, 22]. Therefore, this article focuses on the description of the construction of the fuel rail sub-model. In Figure 1, there is an element indicated by $\mathrm{C}_{-} \mathrm{R}$.

A cylindrical container with defined length and diameter dimensions was adopted for modeling. The container model is a combination of spatial elements with assumed volumes and circular wires with a given diameter and length. Two constructions were adopted that differ in the location of the high pressure pipe connection:

- fuel rail $\mathrm{v}_{-} 1$ - connection along the tray axis to the C_R_6 element - Fig. 2,

- fuel rail $\mathrm{v}_{-}-{ }_{2}-$ connection perpendicular to the storage tank axis to element C_R_95 - Fig. 3.

In both cases, the fuel from the rail is taken by injectors from volumes C_R_1, C_R_18 and C_R_4, which are connected by lines $\bar{C} \_-\bar{R} \_2$ and C_R_3 with a fixed diameter and a defined length of 35,40 and $65 \mathrm{~mm}$. These lengths determine the spacing of injector connections and are marked L_35, L_40 and L_65, respectively. These are the most commonly used spacings of connectors in fuel rails. The parameters of the fuel rails are summarized in Table 1.

The calculations were performed for the conditions corresponding to engine operation at idle and maximum load. Hydraulic boundary conditions were taken for calculations:

- F corresponds to the parameters of fuel fed to the pumping section: pressure $0.3 \mathrm{MPa}$ and temperature $313 \mathrm{~K}$;

- $\mathrm{L}$ - fuel transfer pressure 0.1 MPa and temperature $313 \mathrm{~K}$; 


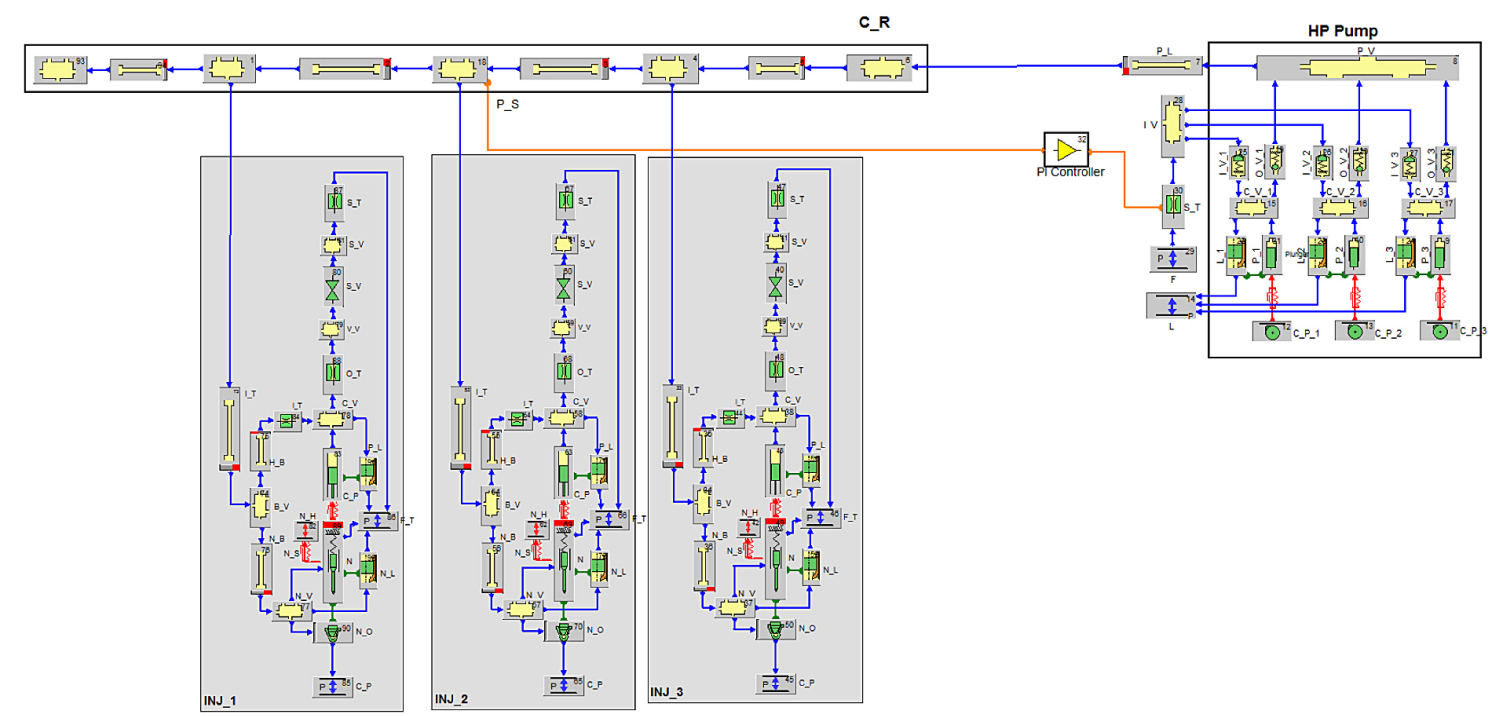

Fig. 1. Model of the fuel supply system.

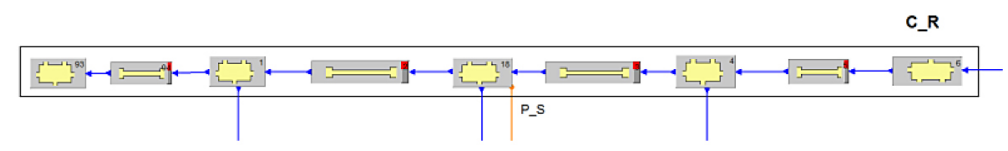

Fig. 2. Fuel rail submodel v_1

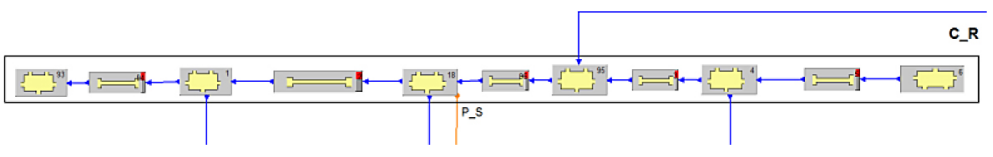

Fig. 3. Fuel rail submodel v_2

Table 1. Fuel rail sub-model parameters

\begin{tabular}{|c|c|c|c|}
\hline Symbol / number in the diagram & Injector element - description & Parametrs & Value \\
\hline C_R / 1, 4, 18 & $\begin{array}{l}\text { Chambers from which fuel is taken by } \\
\text { the injectors }\end{array}$ & volume & $300 \mathrm{~mm}^{3}$ \\
\hline C_R / 6, 95 & $\begin{array}{l}\text { Connection of the high pressure pipe } \\
\text { connecting the pump with the reservoir }\end{array}$ & volume & $200 / 300 \mathrm{~mm}^{3}$ \\
\hline C_R / 2, 3 & Tube, rail volume connection & length; diameter & $\begin{array}{l}\text { 35, } 40 \text { i } 65 \mathrm{~mm} ; 10 \mathrm{~mm} \\
\text { identification } L_{-} 35, L_{-} 40 \\
\text { and } L_{-} 65\end{array}$ \\
\hline C_R / 3, 96 zasobnik v_2 & Tube, rail volume connection & length; diameter & $1 / 2\left(\mathrm{~L} \_35, \mathrm{~L} \_40 \mathrm{i}\right.$ L_65); $10 \mathrm{~mm}$ \\
\hline C_R / 93 & Other volumes & volume & $300 \mathrm{~mm}^{3}$ \\
\hline C_R /5, 94 & Other volumes & length; diameter & $25 \mathrm{~mm} ; 10 \mathrm{~mm}$ \\
\hline
\end{tabular}

- R_P - fuel in the container: pressure $30 \mathrm{MPa}$ for idle and $160 \mathrm{MPa}$ for maximum engine load, temperature $313 \mathrm{~K}$.

The fuel pressure is maintained by the PI_Controler_32 controller, which, based on the indications of the P_S sensor, regulates the flow field through the S_T_30 venturi dispensing the amount of fuel flowing to the section of high pressure pumps. Depending on the set pressure, the proportional and integral components of the regulator were determined.

\section{TEST CONDITIONS AND RESULTS}

\section{Conditions of engine idling}

The following chapter presents the results of the tests carried out on the model with $\mathrm{v}_{-} 1$ rail under idle conditions. The pressure in the highpressure part increases from the supply pressure of $0.3 \mathrm{MPa}$ and is set at $30 \mathrm{MPa}$. Injectors take the mass of fuel in two doses every $120 \mathrm{CAD}$, two doses - pilot and main. 
In the first stage, the test results were compared for the distance between connectors L_35. Figure 4 compares the mass flow of fuel through subsequent injectors (m_INJ_1 - 3). After the pressure in the fuel rail has stabilized, there are differences in the mass flow of fuel through the injectors 1,2 and 3 . The largest difference occurs between injector $2(5.76 \mathrm{~g} / \mathrm{s})$ and $3(5.67 \mathrm{~g} / \mathrm{s})$ and equals $0.09 \mathrm{~g} / \mathrm{s}$. For the main injection dose it is about $1.5 \%$ of the difference in the mass of fuel injected into the combustion chamber.

The differences result from pressure oscillations in the fuel rail. The pressure course in volume C_R_18 is shown below, in which the pressure sensor is mounted. The maximum pressure changes by $0.1 \mathrm{MPa}$ (approx. $0.3 \%$ ) and is the result of the PID controller.

Next, the pressure course was compared for subsequent variants of the distance between the connectors of the lines that are connecting the fuel rail with the injectors. Due to the change in the geometry of the fuel rail, the fuel volumes have changed as well, which has a significant impact on the operation of the entire system. Figure 6 shows the course of fuel pressure in the rail volume C_R_18. An increase in pressure, above the set value, is visible at the initial stage of the system operation (approx. 10 cycles) with increasing distance between the rail stub pipes. The maximum pressure at a selected point at $\mathrm{L}_{-} 35$ is

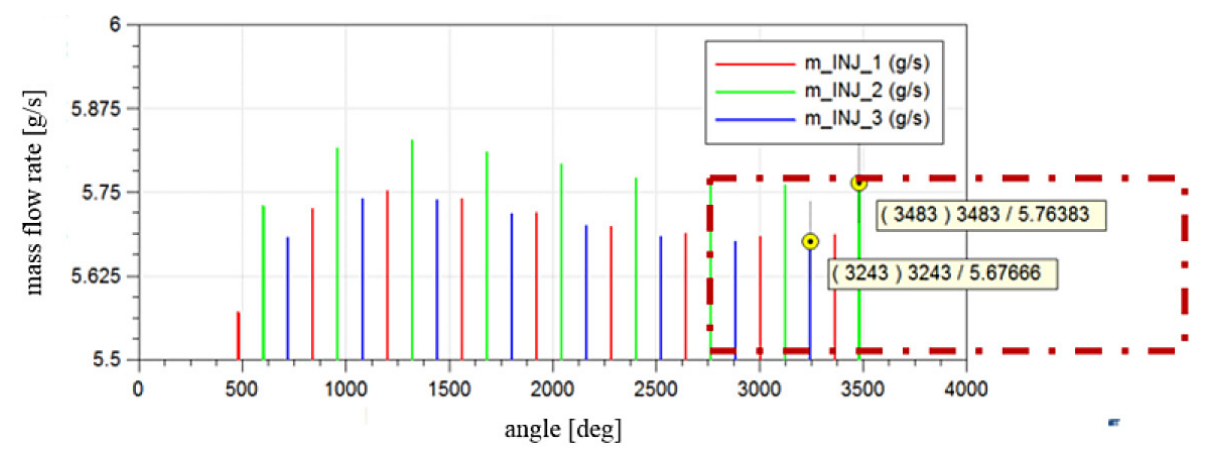

Fig. 4. Fuel mass flow rate through successive atomizers with connection spacing L_35

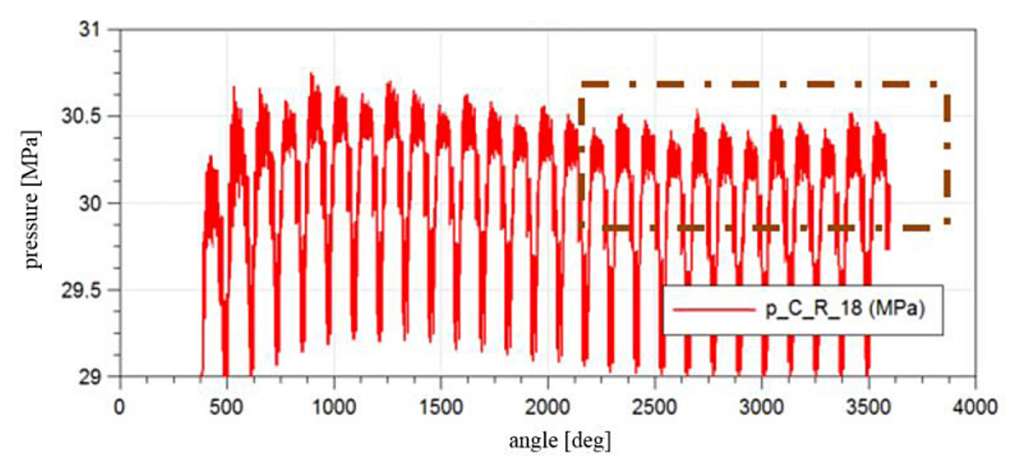

Fig. 5. Pressure in the fuel rail v_1 for $\mathrm{L} \_35$

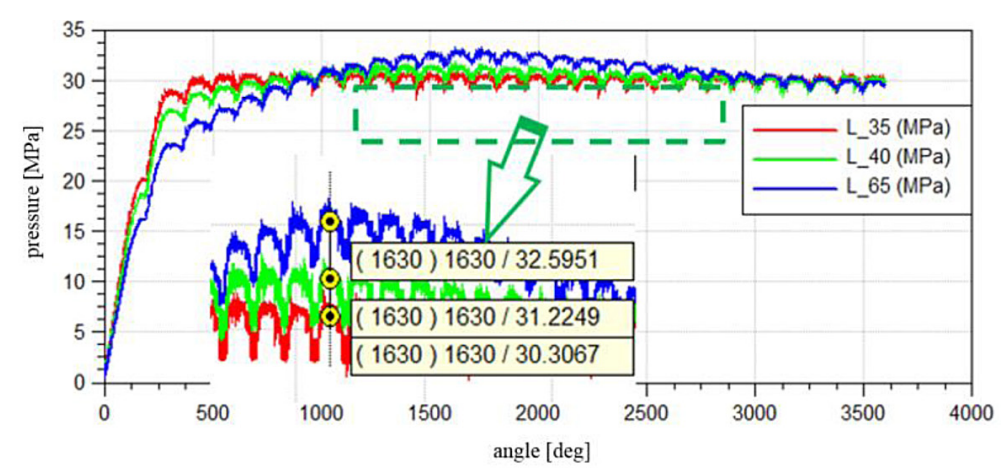

Fig. 6. The course of fuel pressure in the volume $C_{-} R_{-} 18$ of the fuel rail v_1 for the distance between the connectors $L_{-} 35, \overline{L_{-}} 40$ and $L_{-} 65$ 
approx. $30.30 \mathrm{MPa}$ and for $\mathrm{L}_{-} 40-31.22 \mathrm{MPa}$ and for L_65 - $32.59 \mathrm{MPa}$ (percentage from the assumed $30 \mathrm{MPa}$, the difference is: approx. 1, 4 and $9 \%$ respectively). This is due to the use of one PID controller settings selected for length L_ 35 . Changing the length to L_40 and L_65 causes the control system to overshoot. It follows that the optimal parameters of the PID controller should be selected for a given fuel rail geometry.

In the initial state of operation, this translates into a change in the output of the injector. Figure 7 shows the mass flow rate through subsequent atomizers. In order to improve readability for subsequent lengths $\mathrm{L}$, the flow rate from subsequent injectors was presented. Assuming as a reference value the flow rate for $\mathrm{L}_{-} 35-5.73 \mathrm{~g} / \mathrm{s}$, the differences for subsequent lengths are: $\mathrm{L} \_40-6.18 \mathrm{~g} / \mathrm{s}$ (percentage - about $8 \%$ ) and L_65 - $6.49 \mathrm{~g} / \mathrm{s}$ (percentage - approx. $13 \%$ ).

In order to check the injector capacity, depending on the fuel rail version, the mass flow rate through the atomizer of the second injector was compared for the extreme values of the distance between the connectors, i.e. L_35 (Fig. 8) and L_65 (Fig. 9). Regardless of the rail variant, the mass flow values are comparable, so the injector will have the same output. It follows that the method and place of fuel supply to the container do not affect the operation of the fuel injectors and thus their expenditure.

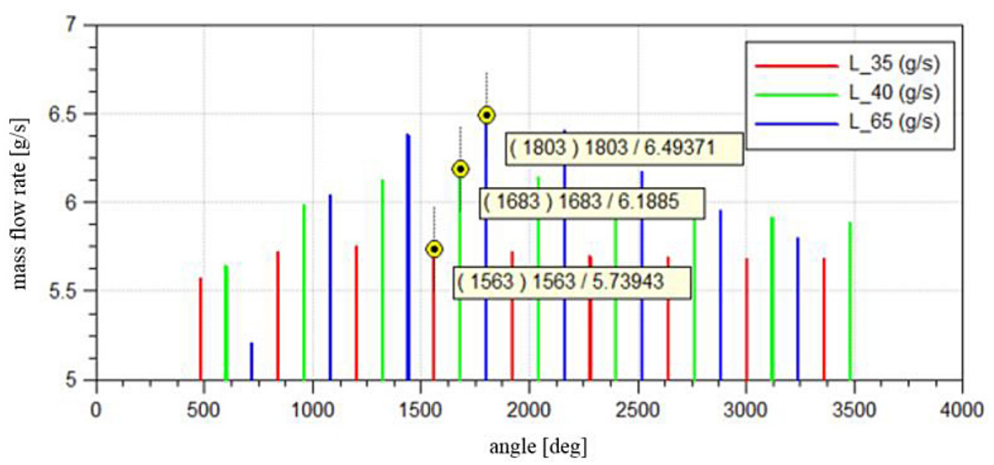

Fig. 7. Mass flow rate through fuel nozzles for distance between stubs L_35, L_40 and L_65 (rail v_1)

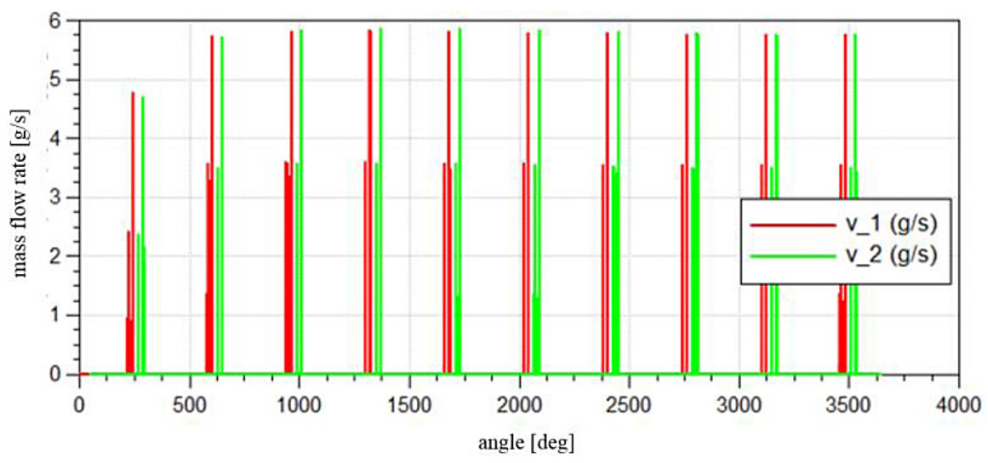

Fig. 8. Mass flow rate through the atomizer of injector 2 for distance between connectors L_35 for rail version v_1 and v_2.

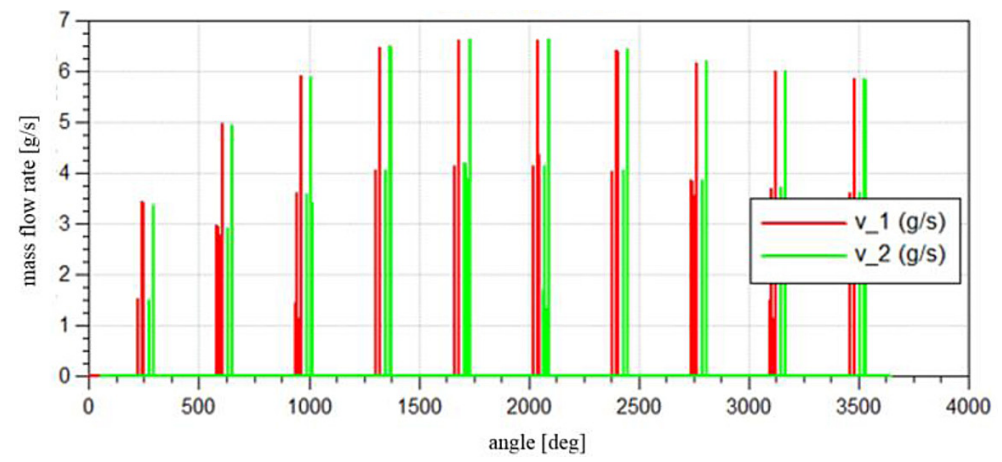

Fig. 9. Mass flow rate through the injector 2 atomizer for distance between connectors L_65 for rail version v_1 and v_2. 


\section{Conditions for maximum engine load}

The results of the tests carried out on the model with a $v_{-} 1$ fuel rail when operating under maximum engine load conditions. The pressure in the high-pressure part increases from the idle pressure of $30 \mathrm{MPa}$ and is set at $160 \mathrm{MPa}$. Injectors take the mass of fuel in one main dose every $120 \mathrm{CAD}$.

Figure 10 compares the mass flow rates of fuel through successive injectors (atomizers) for length L_35. As in the case of idle running, after the pressure in the rail has stabilized, there are differences in the mass flow of fuel through the injector nozzles. The largest difference between injectors is about $0.73 \mathrm{~g} / \mathrm{s}$. For the main injection dose it is about $2.7 \%$ of the difference in the mass of fuel injected into the combustion chamber. The differences result, as in the case of idling, from the operation of the PID controller.

As the tank volume increases, the pressure regulator response is delayed by approx. two engine cycles for the extreme length values L_35 and L_65. Consequently, there is a phase shift of the minimum and maximum fuel pressure in the container. This results in a change in the uniqueness of the fuel dosing by the injectors (Fig. 11). Assuming as a reference value the flow rate for L_65-26.26 g/s, the difference for the minimum length L_35 is about $0.61 \mathrm{~g} / \mathrm{s}$ (percentage - about $2.3 \%$ ). There is no overshoot in the form of exceeding the set pressure. Similarly as in the case of system operation under idle conditions, the optimal controller parameters should be selected for a given geometry of the fuel rail.

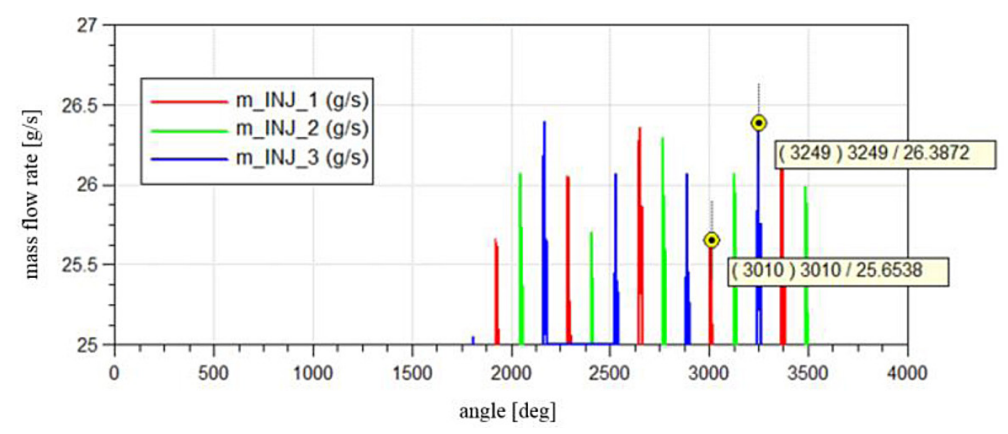

Fig. 10. Mass flow rate of fuel through subsequent nozzles with L_35 spacing (rail v_1)

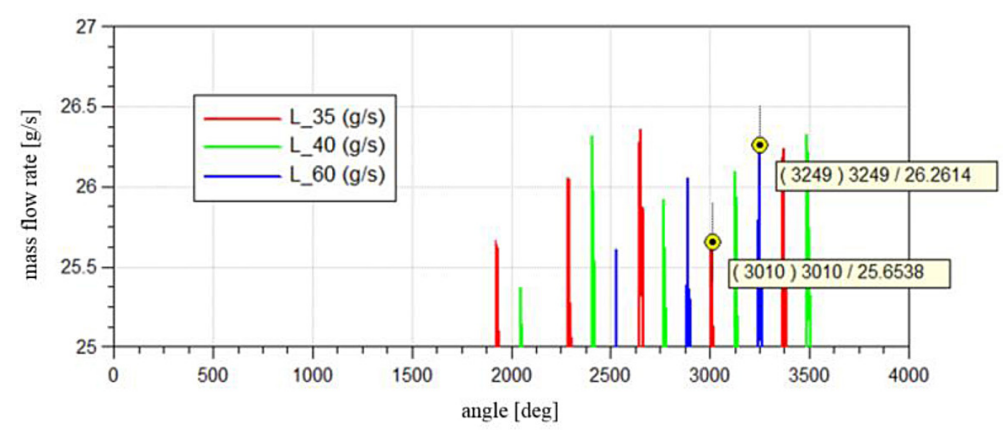

Fig. 11. Mass flow rate through fuel nozzles for distance between connectors $L_{-} 35, L_{-} 40$ and L_60 (rail v_1)

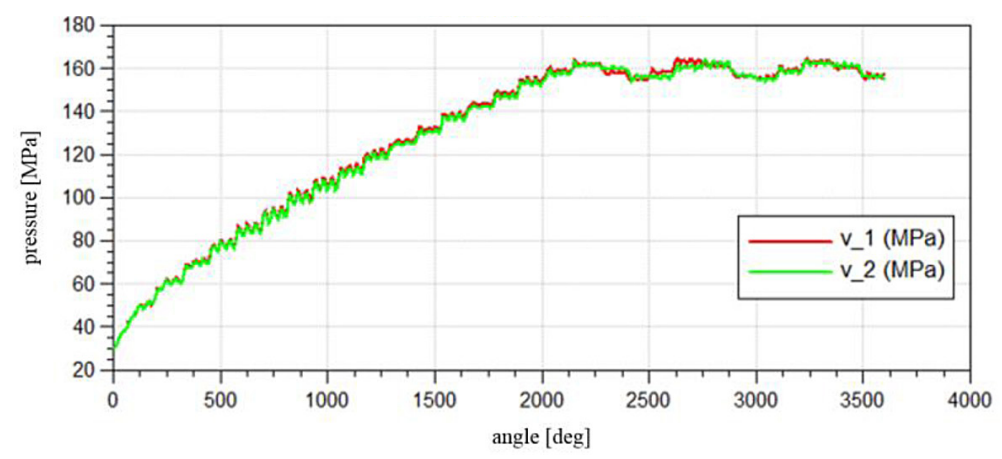

Fig. 12. The course of fuel pressure in the volume of the fuel rail C_R_18 at the distance between the connectors $L_{-} 35$ for the version $v_{-} 1$ and $v_{-} 2$ 


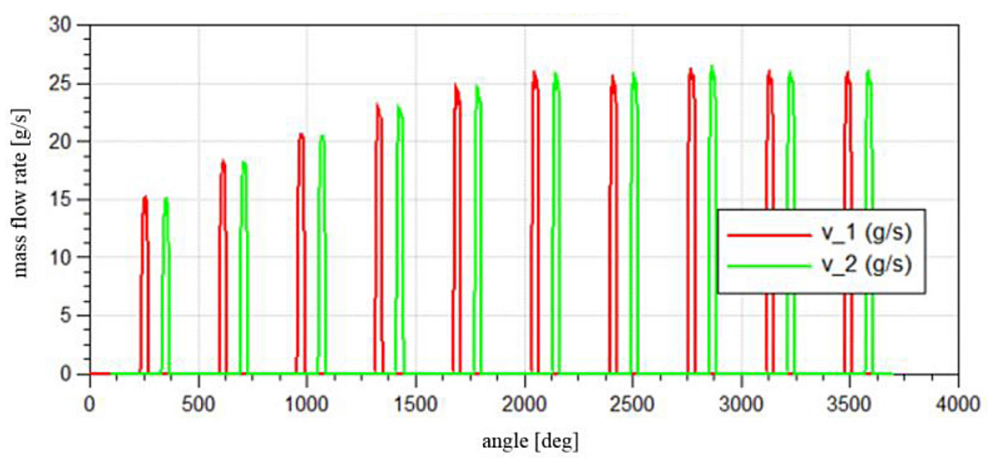

Fig. 13. Mass flow rate through the injector 2 atomizer for distance between connectors $L_{-} 35$ for rail version $v_{-} 1$ and $v \_2$.

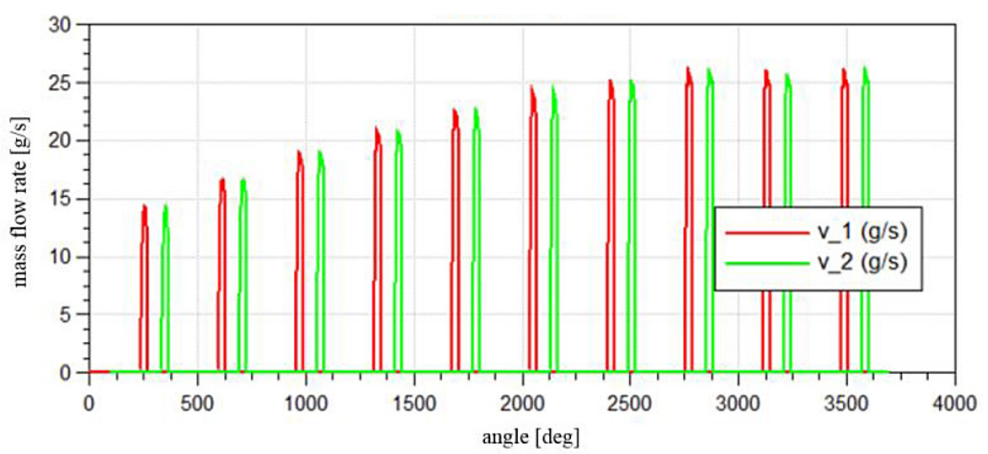

Fig. 14. Mass flow rate through the injector 2 atomizer for distance between connectors L_65 for rail version v_1 and v_2.

In the next stage, for maximum load conditions, the system parameters for rail v_1 and v_2 were compared. Figure 12 shows the fuel pressure waveforms for the distance between connectors L_35 in volume C_R_18 (second injector connection). After reaching the set pressure, the courses coincide after about two cycles and their amplitudes are comparable.

Comparable mass flow rates through the atomizer of the second injector for the extreme values of the distance between the connectors, i.e. L_35 (Fig. 13) and L_65 (Fig. 14) will ensure the same injector flow regardless of the container variant.

\section{CONCLUSIONS}

On the basis of the obtained research results, the following conclusions were drawn:

1. Changing the fuel rail geometry causes the control system to be over-adjusted.

2. Increasing the tray dimensions results in:

- in the case of the system working under idle conditions - system overshoots in the form of exceeding the set pressure,
- in the case of system operation under the conditions of maximum load - overshoot of the system in the form of delayed reaction of the pressure regulator and phase shift of the minimum and maximum fuel pressure in the container, which results in the uniqueness of fuel dosing by injectors.

3. Optimize the PID controller parameters for a given rail geometry should be done.

4. The method of fuel rail supply (version $v_{-} 1$ and v_2) has no effect on the injector output.

5. The geometry of the fuel rail has a greater impact on the operation of the system than the place where the high pressure fuel is fed to the rail.

\section{Acknowledgement}

This work has been realized in the cooperation with The Construction Office of WSK "PZL-KALISZ" S.A. and is part of Grant Agreement No. POIR.01.02.00-00-0002/15 financed by the Polish National Centre for Research and Development. 


\section{REFERENCES}

1. AVL BOOST Hydsim Primer (2013)

2. AVL BOOST Hydsim User Guide (2013)

3. Balluchi A., Bicchi A. Mazzi E., Sangiovanni-Vincentelli A. L., Serra G. Hybrid Multi-rate Control of the Common-Rail. Proceedings of the European Control Conference, 2007.

4. Balluchi A., Bicchi A., Mazzi E., Vincentelli A.S. Serra, G. Hybrid modeling and control of the common rail injection system. International Journal of Control, 2006.

5. Catalano A., Tondolo V.A., Dadone A. Dynamic rise of pressure in the common-rail fuel injection system. SAE Paper No. 2002-01-0210.

6. Czyż, Z., Siadkowska, K., Sochaczewski, R. CFD Analysis of Charge Exchange in an Aircraft Opposed-Piston Diesel Engine. MATEC Web of Conferences, 252, 04002, 2019.

7. Gauthier C., Sename O., Dugard L., Meissonnier G. Modelling of a diesel engine common rail injection system. In: 16th IFAC World Congress, Prague, CZ, IFAC, 2005.

8. Reis H., Reis C., Sharip A., Reis W., Zhao Y., Sinclair R., Beeson L. Diesel exhaust exposure, its multi-system effects, and the effect of new technology diesel exhaust. Environment International 114, 2018, 252-265.

9. He Z.X. Numerical simulation of transient flow in high pressure common rail injector. Journal of Jiangsu University, 2007, 28(2), 142-146.

10. Hu Q., Wu S. F. Modelling of dynamic responses of an automotive fuel rail system, Part I: Injector. Journal of Sound and Vibration, 245(5), 801-814.

11. Jiping L., Shuiyuan T., Yong Z. Simulation of Assembly Tolerance and Characteristics of High Pressure Common Rail Injector. International Journal of Computational Intelligence Systems, 4(6), 2011, 1282-1289.

12. Kamil M., Rahman M. M., Bakar R. A. Modeling of Common Rail Fuel Injection System of Four Cylinder Hydrogen Fueled Engine. Journal of Engineering and Technology, 1(1), 2010.

13. Kalke J., Opaliński M., Szczeciński M. Opposedpiston engines: the future of internal combustion engines? PhD Interdisciplinary Journal, No. 1,
2014, 175-184

14. Liu B. B, Li G. X. Existing status and trend of high pressure common rail injection system in diesel engine. Internal Combustion Engines, 2006, 22(2), $1-3$.

15. Ma FK., Zhao CL., Zhang FJ., Zhao ZF., Zhang ZY., Xie ZY., Wang H. An Experimental Investigation on the Combustion and Heat Release Characteristics of an Opposed-Piston Folded-Cranktrain Diesel Engine. ENERGIES, 8(7), 6365-6381.

16. Magryta P; Geca M. FEM analysis of piston for aircraft two stroke diesel engine. MATEC Web of Conferences, 252, Article Number: 07004, 2018.

17. Payri F., Lujan J. M., Guardiola C., Rizzoni G. Injection diagnosis through common-rail pressure measurement. Proceedings of the Institution of Mechanical Engineers, Part D: Journal of Automobile Engineering, 2006, 220, 347.

18. Pirault JP.; Flint M. Opposed Piston Engines: Evolution, Use, and Future Applications. SAE INTERNATIONAL, 2010.

19. Pogulyaev Y.D., Baitimerov R.M., Rozhdestvenskii Y.V. Detailed dynamic modeling of common rail piezo injector. Procedia Engineering, 129, 2015, 93-98.

20. Sanli A., Yılmaz I. T., Gümüş M. Assessment of combustion and exhaust emissions in a commonrail diesel engine fueled with methane and hydrogen/methane mixtures under different compression ratio. International Journal of Hydrogen Energy, 45(4), 2020, 3263-3283

21. Sochaczewski, R. Modeling fuel injector twostroke diesel engine. Combustion Engines. 170(3), 2017, 147-153.

22. Sochaczewski R., Szlachetka M. Numerical analysis of a fuel pump for an aircraft diesel engine. MATEC Web of Conferences 252, 01003, 2019.

23. Yilmaz I.T., Gumus M. Effects of hydrogen addition to the intake air on performance and emissions of common rail diesel engine. Energy, 142, 2018, 1104-1113.

24. Xu L., Bai X-S., Jia M., Qian Y., Qiao X., Lu X. Experimental and modeling study of liquid fuel injection and combustion in diesel engines with a common rail injection system Applied Energy, 230, 2018, 287-304. 